
\title{
$\begin{array}{ll}\text { Research Square } & \text { Preprints are preliminary reports that have not undergone peer review. } \\ \text { They should not be considered conclusive, used to inform clinical practice, } \\ \text { or referenced by the media as validated information. }\end{array}$
}

\section{Efficacy And Dose Effect Of Intradiscal Injection Of Sustained-Release Simvastatin Hydrogel For Treatment Of Discogenic Low Back Pain In Rabbitsintradiscal}

\author{
Xiaodong Huang ( $\sim$ huangxiaodong08@126.com ) \\ Third Affiliated Hospital of Guangzhou Medical College \\ Weiheng Wang \\ Shanghai Changzheng Hospital \\ Xiaojian Ye \\ Shanghai Changzheng Hospital \\ Chia-Ying Lin \\ University of Cincinnati
}

\section{Zenghui Wu}

Third Affiliated Hospital of Guangzhou Medical College

\section{Research article}

Keywords: simvastatin, discogenic low back pain, intradiscal injection, dose effect, hydrogel

Posted Date: January 25th, 2021

DOI: https://doi.org/10.21203/rs.3.rs-150734/v1

License: (c) (i) This work is licensed under a Creative Commons Attribution 4.0 International License.

Read Full License 


\section{Abstract}

Purpose: The aim of this study was to explore the efficacy and dose effect of intradiscal injection of simvastatin sustained release hydrogel in the treatment of discogenic low back pain in rabbits.

Methods: 36 female rabbits were randomly divided into $\mathrm{G} 1$ and $\mathrm{G} 2$ groups. In group $\mathrm{G} 1, \mathrm{~L} 1 / 2$ was disc degeneration (group DDD), L2/3 was normal group (control group), L3/4 was medium dose treatment group ( $1 \mathrm{mg} / \mathrm{ml}, \mathrm{DDD}+$ medium group), L4/5 was normal group, L5/6 was intervertebral disc degeneration + hydrogel segment (medium group). In group G2, L1 / 2 was degenerative segment, L2 / 3 was normal group, L3 / 4 was low-dose treatment segment (0.3mg/ml, DDD + low-dose group), L4 / 5 was normal group, L5 / 6 was high-dose treatment segment (3mg / ml, DDD + high-dose group). The intervertebral disc was evaluated by X-ray, MRI, water content, and hematoxylin-eosin.

Result: At 12 and 24 weeks after treatment, the\% DHI of control group and DDD + high were higher than those of DDD group and DDD + gel group $(P<0.05)$; $T 2$ image signal of the DDD+High group and Control group is better than DDD group, DDD+GEL group, DDD+ Medium and DDD + Low group $(P<0.05)$.

Intradiscal injection of simvastatin can delay disc degeneration and has a dose effect. At 4 and 12 weeks after treatment, the water content of intervertebral disc in control group and DDD + high group in control group were higher than DDD group, $D D D+$ gel group and DDD + low group $(P<0.05)$.

Conclution $\varangle$ we verified the therapeutic efficacy and dose effect of simvastatin sustained-release system in rabbit DLBP model. The optimal treatment concentration was further optimized based on the dose gradient.

\section{Introduction}

Low back pain (LBP) is one of the most important diseases in clinic. It is a common musculoskeletal disease. With the development of economy and the change of people's living habits, the incidence rate of LBP is increasing year by year. More than $50 \%$ of the general population will experience LBP at some point in their lives. Worldwide, the prevalence of LBP in the general population ranges from 15-45\% [25]. LBP is a serious public health problem, which has a serious economic burden on the society and family, and also has a wide impact on the physical and mental health of patients. Various studies have shown that part of LBP is due to intervertebral disc degeneration [10]. Crock reported for the first time the concept of discogenic low back pain (DLBP) [5]. According to Schwarzer et al., the proportion of DLBP in total LBP is $26-39 \%$ [27].

Up to now, the treatment of DLBP mainly includes conservative treatment (rest, physiotherapy, nerve block with oral drugs and injection of anesthetics), minimally invasive surgery (radiofrequency ablation, endoscopic enucleation) and conventional surgery. Common oral drug treatment includes oral antiinflammatory factors, many inflammatory factors have been confirmed to participate in the process of intervertebral disc degeneration $[1,11]$. Inflammatory factors causing intervertebral disc degeneration include IL-1 a, IL-1 $\beta$, IL-6, IL-17, IL-8, IL-2, IL-4, IL-10, interferon gamma, chemokines and prostaglandin E2 
[30]. At present, many anti-inflammatory agents have been developed, such as infliximab, adalimumab and etanercept [9]. There are also some specific anti-inflammatory drugs, such as IL-1 $\beta$ inhibitor (kineret) and IL- 6 inhibitor (tocilizmab). At present, many treatment methods are well known, but the main problem is that these treatments are very expensive and non-specific. On the other hand, the current biological agents can not relieve long-term pain without drug assistance. Another drug is oral antibiotics, and some scholars believe that intervertebral disc degeneration may be related to bacterial infection of intervertebral disc [6]. This may be due to the elimination of potential bacteria in the intervertebral disc[2], but the detection rate of cells in the intervertebral disc is not high in DLBP patients. These treatments are only aimed at relieving clinical symptoms, and none of them is aimed at specific, potential pathophysiological processes or reversing degeneration.

Recently, with the emergence of recombinant proteins, people began to advocate biological methods to repair or regenerate degenerative intervertebral discs $[18,19]$. For example, an article by Zhang et al found that local injection of simvastatin has the potential to delay intervertebral disc degeneration [35]. Through imaging, histological and genetic evidence, Than et al. showed that intradiscal injection of simvastatin can delay the progression of caudal intervertebral disc degeneration in rats [38, 39]. Statins (HMG CoA reductase inhibitors) were initially used to control and treat patients with hyperlipidemia and hypercholesterolemia [22]. Recently, many studies have shown that statins (simvastatin) can not only regulate inflammation, but also enhance bone induction, promote bone formation and angiogenesis, and inhibit osteoblast apoptosis and osteoclast generation [21, 32]. Since Mundy et al. First reported that statins can promote bone metabolism [22], people have begun to pay attention to the mechanism of statins in human body and verify their anabolism. The current mechanism research results show that simvastatin can promote bone formation by protecting osteoblasts from apoptosis and up regulating BMP-2. In addition, simvastatin reduces osteoclast differentiation and activity, thus reducing bone destruction $[23,40]$. Recent in-depth studies on the process of intervertebral disc degeneration have shown that bone morphogenetic proteins (BMP-2, 5, 6, 8, 9 and 14) play an important role in intervertebral disc degeneration and disc cartilage formation [26, 29, 33]. Zhang et al. Have shown that simvastatin can promote the cartilage expression in rat intervertebral disc cells cultured in vitro, and the possible mechanism is that simvastatin stimulates the expression of endogenous BMP-2 in intervertebral disc cells [37]. This provides a theoretical basis for simvastatin in the treatment of DLBP.

Zhang and Than et al. have shown that local injection of simvastatin has the potential to delay or even reverse the process of intervertebral disc degeneration [38,39]. However, these studies on simvastatin promoting cartilage formation and delaying intervertebral disc degeneration are limited to rat level, and the intervertebral disc degeneration model is located in the caudal intervertebral disc. Their research has the following shortcomings: first, previous studies have been directly injected simvastatin into intervertebral disc, but simvastatin has a very short half-life, which can not achieve long-term therapeutic effect; second, the mechanical structure of rat caudal intervertebral disc is quite different from that of human; third, the caudal intervertebral disc can not simulate the pathophysiological process of DLBP; fourth, the nucleus pulposus and annulus fibrosus cells and human beings There are great differences in morphology and function of the cell like cells, and their response to drugs is different. Therefore, in this 
study, we intend to establish a DLBP model in rabbits, because its anatomical and biomechanical properties are more similar to those of humans. The PEG-PLGA-PEG hydrogel and the simvastatin sustained release system were injected into the lumbar intervertebral disc of rabbits to achieve long-term and effective drug concentration in the intervertebral disc. Imaging and histology were used to evaluate the efficacy of simvastatin sustained release system in the treatment of intervertebral disc degeneration

\section{Methods And Materials}

\section{Experimental animals}

36 6-month-old female New Zealand rabbits (3-3.5 kg) were purchased from Qingdao Kangda Biotechnology Co., Ltd. Each cage $(815 \mathrm{~mm} \times 500 \mathrm{~mm} \times 340 \mathrm{~mm})$ holds one rabbit. These rabbits were housed in a specific room. The air filtration rate was 10-20 air changes per hour; the temperature is 20$26^{\circ} \mathrm{C}$. The humidity was $40-70 \%$, and the fluorescent light is dark for $12 \mathrm{~h}(08: 00-20: 00)$ and then $12 \mathrm{~h}$ every day. These rabbits were housed in an environment where they could eat and drink freely, and adapted to the environment for at least 2 weeks before surgery. All animal operations in this experiment were approved by the Animal Ethics Committee of University of Cincinnati.

\section{Surgical methods}

The animal used in this experiment is a 6-month-old New Zealand male rabbit. At this time, the animal has matured (skeletal muscle, intervertebral disc, etc.), and it will not cause model failure or affect the experimental results due to development. All injectable drugs were administered intramuscularly (i.m.) during the perioperative period. Atropine $(0.2 \mathrm{mg} / \mathrm{kg})$ was administered preoperatively to reduce the production of bronchial secretions during surgery. After about 5-10 minutes, all animals were first anesthetized with Shutai (10-15 mg / kg, i.m.). During surgery, $1.5-3.0 \%$ isoflurane is used to maintain anesthesia, and the oxygen flow used is $0.8-1.5$ liters.

After anesthesia, the rabbits were placed in the left decubitus position to prepare the skin of the pre operation site. lodophor sponge was used to disinfect the puncture site area, and cloth was spread. With the help of C-arm machine and positioning needle, the position of the intervertebral disc to be punctured was determined, and the $21 \mathrm{~g}$ needle was inserted into the intervertebral disc space from $3-4 \mathrm{~cm}$ to the ventral side of spinous process under the fluoroscopy guidance of C-arm machine (Fig. 1a, b). After confirming the puncture needle was located in the center of intervertebral disc space (Fig. 1, e, f), the needle was kept in the space of intervertebral disc for $1 \mathrm{~min}$. Rotate left and right three times before removing the needle. Take out the puncture needle slowly, and then verify the tissue obtained by the needle to determine whether it is nucleus pulposus tissue. Three intervertebral discs (L1 / 2, L3 / 4 and L5 /6) of each rabbit were punctured. No antibiotics and analgesics were used after puncture. After the rabbits were anesthetized and awake, they were put back into the cage after observation.

\section{Animal grouping and Simvastatin treatment}


Two weeks after the puncture, the intervertebral discs were intervened. Because some studies have shown that after 2 weeks of acupuncture, intervertebral disc will appear obvious degeneration [20]. Thirty six female rabbits were randomly assigned to two groups using the body weight based biobook system (IDBS). The usage of rabbits is shown in the table below. The $L 1 / 2$ in group $G 1$ was intervertebral disc degeneration (group DDD), L2/3 was normal group (group Control), L3/4 was used as medium dose treatment segment ( $1 \mathrm{mg} / \mathrm{ml}, \mathrm{DDD}+$ Medium group), L4/5 was normal group, and L5/6 as intervertebral disc degeneration + hydrogel segment (group of Medium). In group G2, L1 / 2 was the degenerative segment, L2 / 3 was the normal group, L3 / 4 was the low-dose treatment segment $(0.3 \mathrm{mg} / \mathrm{ml}$, DDD + low group), L4 / 5 was the normal group, and L5 / 6 was the high-dose treatment segment $(3 \mathrm{mg} / \mathrm{ml}$, DDD + high group).

After anesthesia was successful, the rabbits were operated in the left decubitus position under aseptic operation conditions. At L1 / 2, L3 / 4 and L5 / 6, a $3 \mathrm{~cm}$ long incision was made about 3-4 cm away from spinous process. The L1 / 2, L3 / 4 and L5 / 6 intervertebral discs were exposed through the posterolateral retroperitoneal approach. The degenerative segment of the intervertebral disc was inserted into the intervertebral disc using a miniature syringe connected to a $23 \mathrm{G}$ needle. According to previous studies, $23 \mathrm{G}$ needles did not cause disc degeneration. DDD + Low group, DDD + Medium group and DDD + High group were injected with $10 \mathrm{uL}$ simvastatin $(0.3,1$ or $3 \mathrm{mg} / \mathrm{mL})$ into the corresponding intervertebral disc with a mini syringe. In group DDD + GEL, 10 micron L hydrogel was injected into the corresponding intervertebral disc with a micro syringe. These punctures were carried out under the guidance of X-ray. The direction of the puncture needle was parallel to the upper and lower endplates. The depth of the puncture needle into the intervertebral disc was $5 \mathrm{~mm}$ with hemostatic forceps. The injection time was $1 \mathrm{~min}$. after the injection, the needle was kept in the intervertebral disc for $1 \mathrm{~min}$, and the puncture needle was slowly withdrawn to prevent fluid leakage [31]. At 4, 12 and 24 weeks after intervention, the intervertebral discs were evaluated by imaging and histology. 
Table 1

Grouping and intervention plan

\begin{tabular}{|c|c|c|c|c|}
\hline Group & Information & Quantity & Method & Time point \\
\hline \multirow[t]{4}{*}{ G1 } & $\mathrm{L} 1 / 2$ & 18 & \multirow{9}{*}{$\begin{array}{l}\text { Two weeks after puncture; } \\
\text { intradiscal injection, once }\end{array}$} & \multirow{9}{*}{$\begin{array}{l}4,12,24 \text { weeks after } \\
\text { intervention }\end{array}$} \\
\hline & L3/4 Medium dose & & & \\
\hline & $(1 \mathrm{mg} / \mathrm{mL})$ & & & \\
\hline & L5/6 Hydrogels & & & \\
\hline \multirow[t]{5}{*}{$\mathrm{G} 2$} & $\begin{array}{l}\mathrm{L} 1 / 2 \text { Injured } \\
\text { intervertebral disc }\end{array}$ & 18 & & \\
\hline & L3/4 Medium dose & & & \\
\hline & $(0.3 \mathrm{mg} / \mathrm{mL})$ & & & \\
\hline & L5/6 High dose & & & \\
\hline & (3 mg/mL) & & & \\
\hline
\end{tabular}

\section{Observation on animal health}

The weight and food residue of the rabbits were recorded once a week.

\section{Imaging examination}

Imaging examinations were performed at 4, 12 and 24 weeks after the intervention. After anesthesia, the anteroposterior and lateral films of lumbar vertebrae were taken by $\mathrm{C}$-arm machine. Measurements were made in the median sagittal plane. The disc height index (DHI) was calculated according to Lin's method. $\mathrm{DHI}$ is obtained by averaging the anterior, middle, and posterior heights of IVD and dividing them by the average of adjacent vertebral heights (see figure below). $D H I=2 *(D+E+F) /(A+B+C+G+H+I))$. All images were measured by two independent observers who were not aware of the sample. In order to avoid the possibility of magnification error, the DHI change of the injected disc was normalized to the IVD height of pre injection and expressed as the percentage of $\mathrm{DHI}(\% \mathrm{DHI})$.

MRI was performed before the animals were killed to evaluate the degeneration of intervertebral discs in rabbits. MRI examination of all rabbits was performed using an imager with an orthogonal limb coil receiver Magnetom Skyra 3.0T. In short, the rabbits were anesthetized and placed in prone position for shooting. Double tuned volume RF coil was used to scan the lumbar region of rabbits. Sagittal T2 weighted images covering the whole intervertebral disc region were obtained by spin echo water fat separation technique. The parameters were as follows: repeat time / effective echo time, 3200 / 87 MS; scanning field, 200; turning angle, 150; slice thickness, $1.5 \mathrm{~mm}$; slice spacing, 10\%; scanning times, 2 (total scanning time, $2.3 \mathrm{~min}$ ). Sagittal T2 weighted images covering the entire intervertebral disc region were obtained using quantitative value sequence. The parameters were as follows: repetition time / 
effective echo time, 1230 / 13.8 MS; scanning field, 200; turning angle 180; slice thickness $2 \mathrm{~mm}$; slice spacing, $0 \%$; scanning times, 1 (total scanning time $2.15 \mathrm{~min}$ ).

At the end of the scan, a radiologist who does not know the experimental group is required to circle different segments of the intervertebral disc with the same area, and then the computer will automatically calculate the signal intensity of the T2 weighted image of the region (Fig. 4D).

\section{Water content of intervertebral disc}

After the rabbits were killed, the 11-16 spine of 3 rabbits in each group was obtained. The intervertebral discs were separated from the surrounding soft tissues with a scalpel, marked, and then put back into the refrigerator at $-20{ }^{\circ} \mathrm{C}$ to keep the frozen state. Ten minutes after thawing, the wet weight (WW) of intervertebral disc was recorded by electronic scale with an accuracy of $0.01 \mathrm{mg}$. The samples were then dehydrated at $65^{\circ} \mathrm{C}$ for $24 \mathrm{~h}$, and then the dry disc weight (DW) was recorded at the same ratio. Wet and dry weights were measured three times and the average values were used for subsequent analysis. The percentage of disc water content was calculated as ((WW-DW) / WW $) \times 100 \%$.

\section{Histological evaluation}

After the rabbits were killed, the L1-L6spine of 3 rabbits in each group was obtained. These tissues were fixed in $4 \%$ formaldehyde for at least $48 \mathrm{~h}$. Then they were decalcified in $22.5 \%$ formic acid and $10 \%$ sodium citrate for 5-7 days. Decalcification was periodically verified by X-ray photography. They were then embedded in paraffin and sectioned in sagittal (10 $\mu \mathrm{m}$ thick) with a microtome. Sections were stained with hematoxylin and eosin ( $\mathrm{H} \& \mathrm{E})$, and then qualitatively analyzed with Olympus optical microscope at magnification range from 40 to 200. According to the evaluation method in Table 2, the histological results of HE staining were observed and scored. 
Table 2

Histological rating scale

\begin{tabular}{|c|c|c|}
\hline Content & Grade & Grade Description \\
\hline \multirow[t]{3}{*}{ I. Annulus fibrosus } & 1 & $\begin{array}{l}\text { Normal pattern of fibrocartilage lamellae (U-shaped in the posterior } \\
\text { aspect and slightly convex in the anterior aspect) without ruptured } \\
\text { fibers and without a serpentine appearance anywhere within the } \\
\text { annulus }\end{array}$ \\
\hline & 2 & $\begin{array}{l}\text { Ruptured or serpentine-patterned fibers in less than } 30 \% \text { of the } \\
\text { annulus }\end{array}$ \\
\hline & 3 & $\begin{array}{l}\text { Ruptured or serpentine-patterned fibers in more than } 30 \% \text { of the } \\
\text { annulus }\end{array}$ \\
\hline \multirow{3}{*}{$\begin{array}{l}\text { II. Border between } \\
\text { the annulus fibrosus } \\
\text { and nucleus } \\
\text { pulposus }\end{array}$} & 1 & Normal \\
\hline & 2 & Minimally interrupted \\
\hline & 3 & Moderate / severe interruption \\
\hline \multirow[t]{3}{*}{$\begin{array}{l}\text { III. Cellularity of the } \\
\text { nucleus pulposus }\end{array}$} & 1 & $\begin{array}{l}\text { Normal cellularity with large vacuoles in the gelatinous structure of } \\
\text { the matrix }\end{array}$ \\
\hline & 2 & Slight decrease in the number of cells and fewer vacuoles \\
\hline & 3 & $\begin{array}{l}\text { Moderate/severe decrease }(>50 \%) \text { in the number of cells and no } \\
\text { vacuoles }\end{array}$ \\
\hline \multirow{3}{*}{$\begin{array}{l}\text { IV. Matrix of the } \\
\text { nucleus pulposus }\end{array}$} & 1 & Normal gelatinous appearance \\
\hline & 2 & Slight condensation of the extracellular matrix \\
\hline & 3 & Moderate/severe condensation of the extracellular matrix \\
\hline
\end{tabular}

\section{Clinical blood and urine examination}

Blood and urine samples of all rabbits were collected before the experiment and before being executed. The blood routine, blood biochemistry and urine routine of all animals were analyzed and evaluated.

\section{Statistical analysis}

PASW statistics 21.0 (SPSS Inc.) software was used for data analysis and graph pad prism 8 software was used for mapping. All experimental data were expressed as mean \pm SD. One way ANOVA was used for intra group comparison, while variance of repeated measurement design was used for inter group comparison. In order to standardize the histological data, we used the histological grade of normal control discs as the reference group. $\mathrm{P}<0.05$ means the difference is statistically significant.

\section{Results}




\section{Effect of intradiscal injection of drugs on animal weight}

After the establishment of DLBP model by acupuncture of intervertebral disc, the weight of rabbits in the two groups began to decline, and it dropped to the lowest point one week after puncture, and then the weight of rabbits in the two groups gradually increased. There was no significant difference in the weight between the two groups $(P>0.05)$. At this time, the degenerative disc was intervened under direct vision. After treatment, the weight of rabbits in the two groups began to decline, and there was no significant difference between the two groups $(P>0.05)$. At the second week after the intervention, the weight of rabbits in both groups gradually increased, and there was no significant difference between the two groups $(P>0.05)$. The steady weight gain of all rabbits showed that the rabbits could tolerate the operation well.

\section{Effects of intradiscal injection of drugs on food residues in animals}

After the establishment of DLBP model by acupuncture at intervertebral disc, the amount of food residue in the two groups began to increase, and reached the highest point one week after puncture. There was no significant difference in food residue between the two groups $(P>0.05)$. After the intervention of intervertebral disc, the food residue of the two groups began to increase, and gradually decreased from the second week after treatment. There was no significant difference in food residue between the two groups $(P>0.05)$. This indicates that intradiscal injection of simvastatin has no significant effect on rabbit appetite, which further indicates that all rabbits can well tolerate surgery and adapt to the relevant feeding environment.

Figure 6 Effect of intradiscal injection of drugs on food residue in animals. The graph shows the change of food residues in rabbits over time. All data were expressed as mean $\pm S D(n=6)$.

\section{Effect of intradiscal injection of drugs on intervertebral height index in animals}

In order to evaluate the change of disc height over time, lumbar disc X-ray were taken in the 24 week group and\% DHI was calculated. After treatment of degenerative intervertebral disc, the\% DHI of DDD group and DDD + gel group decreased gradually; the\% DHI of DDD + medium group increased slightly; the\% $\mathrm{DHI}$ of DDD + low group remained basically unchanged; and\% DHI of DDD + high group increased gradually. At the 4th week after the drug injection, the \%DHI of the DDD group and DDD + GEL group was lower than that of the Control group $(p=0.0406, p=0.0211)$. At 12 and 24 weeks after injection, the\% DHI of control group $(P<0.0001, P=0.0211 ; P<0.0001, P=0.0211)$ and $D D D+$ high $(P=0.0211, P=0.0353 ; P$ $=0.0211, P=0.0448$ ) were higher than those of DDD group and DDD + gel group. This indicates that simvastatin can delay or even reverse the loss of disc height, and has a dose effect.

\section{Effect of intradiscal injection of drugs on MRI of animal intervertebral discs}


The signal intensity of T2 images on MRI was used to evaluate the condition and water content of intervertebral disc. At 4 weeks after DLBP treatment, the T2 signal intensity of DDD + high group $(P=$ $0.0221, P=0.0248, P=0.0138, P=0.0292)$ and control group $(P=0.0148, P=0.0141, P=0.0271, P<$ 0.0001 ) were higher than those in $\mathrm{DDD}$ group, $\mathrm{DDD}+$ gel group, $\mathrm{DDD}+$ medium group and $\mathrm{DDD}+\mathrm{low}$ group. At 12 and 24 weeks after DLBP treatment, T2 image signal of the DDD + High group $(p=0.0016, p$ $=0.0007, p=0.0002, p=0.0142 ; p=0.0124, p=0.0265, p=0.0290, p=0.0095)$ and Control group $(P=$ $0.0278, p=0.0347, p=0.0404, p=0.0154 ; p=0.0279, p=0.0446, p=0.0240, p=0.0004)$ is better than DDD group, DDD + GEL group, DDD + Medium and DDD + Low group. This indicates that simvastatin can increase the signal of $\mathrm{T} 2$ image of intervertebral disc MRI, and has dose effect.

\section{Effect of intradiscal injection of simvastatin on histological score of intervertebral disc}

In annulus fibrosus, the histological scores of control group $(P<0.0001, P<0.0001)$ and DDD + high group $(P=0.0190, P=0.0048)$ were lower than those of DDD group and DDD + gel group. Compared with DDD group, DDD + gel group and DDD + low group, the histological score of intervertebral disc in control group was lower than that in DDD group, $D D D+$ gel group and DDD + low group $(P<0.0001, P=0.0002, P$ $=0.0226)$, and the histological score of intervertebral disc in DDD + high group was lower than that in DDD group $(P=0.0226)$. The number and morphology of nucleus pulposus cells in control group were lower than those in DDD group, DDD + gel group and DDD + low group $(P<0.0001, P=0.0002, P=$ 0.0043); the histological score of intervertebral disc in DDD + high group was lower than that in DDD group and $D D D+$ gel group $(P=0.0226, P=0.0232)$. Compared with DDD group, $D D D+$ gel group, $D D D+$ low group and DDD + medium group, the histological score of control group was lower than that of DDD group, $D D D+$ gel group, $D D D+$ low group and $D D D+$ medium group $(P<0.0001, P=0.0043, P=0.0181, P$ $=0.0048$ ); the histological score of intervertebral disc in DDD + high group was lower than that in DDD group $(P=0.0190)$. These results suggest that intradiscal injection of simvastatin can delay disc degeneration and has a dose effect.

\section{Effect of intradiscal injection of simvastatin on the water content of intervertebral disc}

At 4 and 12 weeks after intradiscal injection of simvastatin, the water content of intervertebral disc in control group $(P<0.0001, P=0.0105, P=0.0411 ; P=0.0322, P=0.0106, P=0.0276)$ and $D D D+$ high group $(P=0.0411, P=0.0180, P=0.0123 ; P=0.0302, P=0.0392, P=0.0348)$ in control group were higher than those in DDD group, DDD + gel group and DDD + low group. At 24 weeks after intradiscal injection of simvastatin, the water content of intervertebral disc in control group was higher than that in DDD group, $D D D+$ gel group and $D D D+$ low group $(P=0.0004, P=0.0057, P=0.0105)$, and that of $D D D+$ high group was higher than that of DDD group and DDD + gel group $(P=0.0052, P=0.0446)$. These data suggest that intradiscal injection of simvastatin can increase the water content of intervertebral disc and has a dose effect. 
Figure 10 the effect of simvastatin on the water content of intervertebral disc. This graph shows the change of water content of intervertebral disc with time. All data were expressed as mean $\pm S D, * P<0.05$ vs. DDD group, \#P<0.05 vs. DDD + gel group, \& $P<0.05$ vs. DDD + low group $(n=3)$.

\section{Detection of blood and urine}

There was no significant difference in blood routine test, blood biochemistry test and urine routine test between the two groups $(P>0.005)$. It is suggested that simvastatin injection into intervertebral disc will not affect the blood routine, blood biochemistry and urine routine of animals.

\section{Discussion}

Since the concept of DLBP was first proposed by crock in 1970 [5]. People have further understanding of intervertebral disc disease, and think that DLBP is to exclude disc herniation and joint surface pain in symptoms [15], and to exclude low back pain caused by intervertebral disc degeneration (intervertebral disc structure disorder) in imaging [24]. Although the study of intervertebral disc has lasted for many years, there is still a lack of diagnostic criteria for DLBP. Discography is an important method to diagnose DLBP. Discography was first proposed by Lindbloom in 1948. It is an invasive diagnostic technique by injecting contrast agent into intervertebral disc to observe the shape of intervertebral disc [4], which has been controversial since the beginning of Invention $[3,16,36]$. Although there are controversies, discography is widely used in clinical practice. It has the advantages that other examination items can't replace: typical pain duplication, fine and intuitive display of intervertebral disc injury. A systematic review showed that: according to the International Association for pain research (IASP) standard, discography may be a useful tool for evaluating chronic discogenic pain [16], and some articles also confirmed that CT examination immediately after discography is the "gold standard" for the diagnosis of DLBP [28]. Simvastatin used in this experiment can be injected into the suspected diseased intervertebral disc together with contrast agent or blocking agent during discography and intervertebral disc block. On the one hand, it can play an auxiliary role in diagnosis, on the other hand, it can assist in treatment.

Simvastatin is a widely studied and well tolerated drug, which is known to upregulate the expression of BMP-2A [37]. Simvastatin, an inhibitor of HMG CoA reductase, is a traditional cheap lipid-lowering drug. It interferes with liver cholesterol synthesis by inhibiting HMG CoA reductase, an enzyme involved in cholesterol production through the mevalonate pathway [8]; therefore, statins can reduce serum cholesterol levels and significantly reduce mortality associated with coronary heart disease $[12,17]$. Zhang et al. have shown that simvastatin can increase the expression of BMP-2 mRNA in rats [37]. At the same time, it can also up regulate the gene expression of glycosaminoglycan and type II collagen and the content of proteoglycan, which indicates that simvastatin can enhance the function of intervertebral disc cell synthesis. This provides a theoretical basis for choosing simvastatin in the treatment of DLBP. The results of body weight change, food residue and routine hematuria showed that simvastatin injection into intervertebral disc had no adverse effect on animals. 
The clinical manifestation of DLBP is the decrease of intervertebral space height and the decrease of water signal on T2 image of MRI. Although MRI has been widely considered as a sensitive index in the diagnosis of DLBP, the traditional MRI technology has not fully evaluated the early degeneration of intervertebral disc [14]. This study is one of the first studies to evaluate early intervertebral disc degeneration, such as changes in extracellular matrix, especially changes in water signal, using the newly developed specialized MRI technology (T2 anchor technique) [7,34]. The best way to repair the intervertebral disc is to protect the uninjured disc tissue as much as possible, and increase the expression of water containing substances (type 2 collagen and glycosaminoglycan) in the intervertebral disc to maintain its seismic resistance. At present, most of the latest biological therapy methods are based on the above theory, such as autologous cell transplantation, injection of growth factor and gene therapy. This study aims to verify a promising treatment method, which is easier for clinical transformation. Our results show that a single dose of simvastatin can reduce the loss of disc height, and DDD + high group can reduce the loss of disc height. At the same time, the three concentrations of simvastatin injected into the intervertebral disc can increase the T2 image water signal intensity of intervertebral disc MRI, and the high-dose simvastatin treatment group can increase the T2 image water signal intensity of intervertebral disc MRI. Simvastatin can increase the water content of the intervertebral disc. These results suggest that intradiscal injection of simvastatin can reduce disc degeneration, which is consistent with previous studies that local injection of simvastatin in rats has delayed or regenerative degenerative discs [39]. At the same time, we also found that simvastatin has dose effect in the treatment of intervertebral disc degeneration.

In this study, we used a simple X-ray photography technique designed by Lü et al. To measure the intervertebral disc height: DHI [13]. In order to measure more accurately, we try the following aspects. First, we try to keep the rabbits in the same anesthesia state and maintain consistent muscle relaxation to minimize the difference in disc height. Second, recheck and adjust the rabbit's position before shooting until the projection of spinous process of rabbit's spine is located in the middle line of cone in the AP film; the projection of two transverse processes of spine overlaps in lateral film, indicating that the true anteroposterior and lateral films have been obtained (Fig. 3a, b). Third, keep the animal spine in a fixed position and aim at the X-ray beam to reduce the error caused by spinal rotation and beam divergence. In addition, measurements were repeated to minimize any inter subject variability in\% $\mathrm{DHI}$ after disc puncture.

However, there are some shortcomings in this experiment, including the following points. First of all, acupuncture injection was used for intradiscal administration, and acupuncture itself destroyed the structural integrity of the intervertebral disc, resulting in intervertebral disc degeneration, which was directly related to the diameter of puncture needle. Although the needle with smaller diameter was used for drug administration in this experiment, and parallel control was conducted, the influence of acupuncture itself on intervertebral disc degeneration still could not be ruled out. At present, there is no ideal way of administration, which needs further study. Secondly, the longest experimental observation time of this study is only 6 months. We only observed the short-term and medium-term efficacy of simvastatin injection into degenerative intervertebral disc. Therefore, in future experiments, we will extend 
the observation time to determine whether the drug has a long-term therapeutic effect on intervertebral disc. Thirdly, the treatment of degenerative intervertebral disc was not randomized, and the selection of treatment segments was not randomized. Then the MRI examination to judge the degree of intervertebral disc degeneration in the experiment is to get the result by comparing the treated intervertebral disc with adjacent normal intervertebral disc, rather than comparing with the MRI before the treatment of the same intervertebral disc, which is easy to produce systematic error. Finally, the subjects of this study are New Zealand rabbits, which are reptiles, which are quite different from human beings. Therefore, in the following experiments, we will choose standing animals that are closer to human beings, such as monkeys, for preclinical trials. Due to the practical operation problems of ethics, the human body test has not been studied in this experiment, so the human body test needs to be further studied.

\section{Conclusion}

In this study, we verified the therapeutic efficacy and dose effect of simvastatin sustained-release system in rabbit DLBP model. The optimal treatment concentration was further optimized based on the dose gradient. Combined with our previous studies, these new data further support the potential clinical strategy of simvastatin as an effective treatment for DLBP. It will lay a more solid experimental and theoretical foundation for the clinical application of simvastatin.

\section{Declarations}

\section{Acknowledgments}

\section{Authors' contributions}

I.Xiaodong Huang MD PhD, orthopaedic surgeon: Substantial contributions to the research design, data acquisition, statisti- cal analysis, drafting the paper and revising it critically; Weiheng Wang MD PhD, orthopaedic surgeon: Data acquisition, approval of the submitted and final version; Xiaojian Ye MD, PhD, orthopaedic surgeon: Data acquisition, approval of the submitted and final version; Chia- Ying Lin MD, orthopaedic surgeon: Data acquisition, approval of the submitted and final version; Zenghui Wu MD, PhD, Surgery supervisor, substantial con- tributions to the research design, data acquisition, approval of the submitted and final version.

Funding: This project was supported by National Natural Science Foundation of China (Grant Nos. 81672178).

Conflict of interest :The authors declare that they have no conflict of interest.

Ethical approval[The study was approved by the Animal Care and Use Committee of university of Cincinnati.

Data availability All data generated or analysed during this study are included in this published article. 
Consent for publication पAll the authors agree with the publication of this article.

\section{References}

1. Ahn SH, Cho YW, Ahn MW, Jang SH, Sohn YK, Kim HS (2002) mRNA expression of cytokines and chemokines in herniated lumbar intervertebral discs. Spine 27:911-917

2. Albert HB, Sorensen JS, Christensen BS, Manniche C (2013) Antibiotic treatment in patients with chronic low back pain and vertebral bone edema (Modic type 1 changes): a double-blind randomized clinical controlled trial of efficacy. European spine journal : official publication of the European Spine Society, the European Spinal Deformity Society, and the European Section of the Cervical Spine Research Society 22:697-707. doi: 10.1007/s00586-013-2675-y

3. Carragee EJ (2001) Psychological and functional profiles in select subjects with low back pain. The spine journal : official journal of the North American Spine Society 1:198-204

4. Collis JS, Jr., Gardner WJ (1962) Lumbar discography. An analysis of one thousand cases. Journal of neurosurgery 19:452-461. doi: 10.3171/jns.1962.19.6.0452

5. Crock HV (1970) A reappraisal of intervertebral disc lesions. The Medical journal of Australia 1:983989

6. Drago L, Romano CL, Cecchinato R, Villafane JH, De Vecchi E, Lamartina C, Berjano P (2017) Are MODIC Type 2 disc changes associated with low-grade infections? A pilot study. Journal of neurosurgical sciences. doi: 10.23736/s0390-5616.17.03997-2

7. Ellingson AM, Nagel TM, Polly DW, Ellermann J, Nuckley DJ (2014) Quantitative T2* (T2 star) relaxation times predict site specific proteoglycan content and residual mechanics of the intervertebral disc throughout degeneration. Journal of orthopaedic research : official publication of the Orthopaedic Research Society 32:1083-1089. doi: 10.1002/jor.22633

8. Goldstein JL, Brown MS (1990) Regulation of the mevalonate pathway. Nature 343:425-430. doi: $10.1038 / 343425 \mathrm{a} 0$

9. Goupille P, Mulleman D, Paintaud G, Watier H, Valat JP (2007) Can sciatica induced by disc herniation be treated with tumor necrosis factor alpha blockade? Arthritis and rheumatism 56:38873895. doi: 10.1002/art.23051

10. Kallewaard JW, Geurts JW, Kessels A, Willems P, van Santbrink H, van Kleef M (2016) Efficacy, Safety, and Predictors of Intradiscal Methylene Blue Injection for Discogenic Low Back Pain: Results of a Multicenter Prospective Clinical Series. Pain practice : the official journal of World Institute of Pain 16:405-412. doi: 10.1111/papr.12283

11. Kang YM, Suk KS, Lee BH, Kim HS, Lee KI, Park SY, Lee HM, Moon SH (2014) Herniated intervertebral disk induces hypertrophy and ossification of ligamentum flavum. Journal of spinal disorders \& techniques 27:382-389. doi: 10.1097/BSD.0b013e3182a26532

12. LaRosa JC, He J, Vupputuri S (1999) Effect of statins on risk of coronary disease: a meta-analysis of randomized controlled trials. Jama 282:2340-2346 
13. Lu DS, Shono Y, Oda I, Abumi K, Kaneda K (1997) Effects of chondroitinase ABC and chymopapain on spinal motion segment biomechanics. An in vivo biomechanical, radiologic, and histologic canine study. Spine 22:1828-1834; discussion 1834-1825

14. Luoma K, Vehmas T, Riihimaki H, Raininko R (2001) Disc height and signal intensity of the nucleus pulposus on magnetic resonance imaging as indicators of lumbar disc degeneration. Spine 26:680686

15. Manchikanti L, Abdi S, Atluri S, Benyamin RM, Boswell MV, Buenaventura RM, Bryce DA, Burks PA, Caraway DL, Calodney AK, Cash KA, Christo PJ, Cohen SP, Colson J, Conn A, Cordner H, Coubarous S, Datta S, Deer TR, Diwan S, Falco FJ, Fellows B, Geffert S, Grider JS, Gupta S, Hameed H, Hameed M, Hansen H, Helm S, 2nd, Janata JW, Justiz R, Kaye AD, Lee M, Manchikanti KN, McManus CD, Onyewu O, Parr AT, Patel VB, Racz GB, Sehgal N, Sharma ML, Simopoulos TT, Singh V, Smith HS, Snook LT, Swicegood JR, Vallejo R, Ward SP, Wargo BW, Zhu J, Hirsch JA (2013) An update of comprehensive evidence-based guidelines for interventional techniques in chronic spinal pain. Part Il: guidance and recommendations. Pain physician 16:S49-283

16. Manchikanti L, Benyamin RM, Singh V, Falco FJ, Hameed H, Derby R, Wolfer LR, Helm S, 2nd, Calodney AK, Datta S, Snook LT, Caraway DL, Hirsch JA, Cohen SP (2013) An update of the systematic appraisal of the accuracy and utility of lumbar discography in chronic low back pain. Pain physician 16:Se55-95

17. Maron DJ, Fazio S, Linton MF (2000) Current perspectives on statins. Circulation 101:207-213

18. Masuda K (2008) Biological repair of the degenerated intervertebral disc by the injection of growth factors. European spine journal : official publication of the European Spine Society, the European Spinal Deformity Society, and the European Section of the Cervical Spine Research Society 17 Suppl 4:441-451. doi: 10.1007/s00586-008-0749-z

19. Masuda K, An HS (2006) Prevention of disc degeneration with growth factors. European spine journal : official publication of the European Spine Society, the European Spinal Deformity Society, and the European Section of the Cervical Spine Research Society 15 Suppl 3:S422-432. doi: 10.1007/s00586-006-0149-1

20. Masuda K, Aota Y, Muehleman C, Imai Y, Okuma M, Thonar EJ, Andersson GB, An HS (2005) A novel rabbit model of mild, reproducible disc degeneration by an anulus needle puncture: correlation between the degree of disc injury and radiological and histological appearances of disc degeneration. Spine 30:5-14

21. Moshiri A, Shahrezaee M, Shekarchi B, Oryan A, Azma K (2015) Three-Dimensional Porous GelapinSimvastatin Scaffolds Promoted Bone Defect Healing in Rabbits. Calcified tissue international 96:552-564. doi: 10.1007/s00223-015-9981-9

22. Mundy G, Garrett R, Harris S, Chan J, Chen D, Rossini G, Boyce B, Zhao M, Gutierrez G (1999) Stimulation of bone formation in vitro and in rodents by statins. Science (New York, NY) 286:19461949 
23. Oryan A, Kamali A, Moshiri A (2015) Potential mechanisms and applications of statins on osteogenesis: Current modalities, conflicts and future directions. Journal of controlled release : official journal of the Controlled Release Society 215:12-24. doi: 10.1016/j.jconrel.2015.07.022

24. Park WM, McCall IW, O'Brien JP, Webb JK (1979) Fissuring of the posterior annulus fibrosus in the lumbar spine. The British journal of radiology 52:382-387. doi: 10.1259/0007-1285-52-617-382

25. Parreira P, Maher CG, Steffens D, Hancock MJ, Ferreira ML (2018) Risk factors for low back pain and sciatica: an umbrella review. The spine journal : official journal of the North American Spine Society 18:1715-1721. doi: 10.1016/j.spinee.2018.05.018

26. Rickert M (2008) BMP-14 gene therapy increases tendon tensile strength in a rat model of achilles tendon injury. The Journal of bone and joint surgery American volume 90:445; author reply 445-446

27. Schwarzer AC, Aprill CN, Derby R, Fortin J, Kine G, Bogduk N (1994) The relative contributions of the disc and zygapophyseal joint in chronic low back pain. Spine 19:801-806

28. Schwarzer AC, Aprill CN, Derby R, Fortin J, Kine G, Bogduk N (1995) The prevalence and clinical features of internal disc disruption in patients with chronic low back pain. Spine 20:1878-1883

29. Sekiya I, Colter DC, Prockop DJ (2001) BMP-6 enhances chondrogenesis in a subpopulation of human marrow stromal cells. Biochemical and biophysical research communications 284:411-418. doi: $10.1006 /$ bbrc. 2001.4898

30. Shim EK, Lee JS, Kim DE, Kim SK, Jung BJ, Choi EY, Kim CS (2016) Autogenous Mesenchymal Stem Cells from the Vertebral Body Enhance Intervertebral Disc Regeneration via Paracrine Interaction: An in Vitro Pilot Study. Cell transplantation 25:1819-1832. doi: 10.3727/096368916×691420

31. Silveira JW, Issy AC, Castania VA, Salmon CE, Nogueira-Barbosa MH, Guimaraes FS, Defino HL, Del Bel E (2014) Protective effects of cannabidiol on lesion-induced intervertebral disc degeneration. PloS one 9:e113161. doi: 10.1371/journal.pone.0113161

32. Skoglund B, Forslund C, Aspenberg P (2002) Simvastatin improves fracture healing in mice. Journal of bone and mineral research : the official journal of the American Society for Bone and Mineral Research 17:2004-2008. doi: 10.1359/jbmr.2002.17.11.2004

33. Snelling SJ, Hulley PA, Loughlin J (2010) BMP5 activates multiple signaling pathways and promotes chondrogenic differentiation in the ATDC5 growth plate model. Growth factors (Chur, Switzerland) 28:268-279. doi: 10.3109/08977191003752296

34. Stelzeneder D, Kovacs BK, Goed S, Welsch GH, Hirschfeld C, Paternostro-Sluga T, Friedrich KM, Mamisch TC, Trattnig S (2012) Effect of short-term unloading on T2 relaxation time in the lumbar intervertebral disc-in vivo magnetic resonance imaging study at 3.0 tesla. The spine journal : official journal of the North American Spine Society 12:257-264. doi: 10.1016/j.spinee.2012.02.001

35. Than KD, Rahman SU, Wang L, Khan A, Kyere KA, Than TT, Miyata Y, Park YS, La Marca F, Kim HM, Zhang H, Park P, Lin CY (2014) Intradiscal injection of simvastatin results in radiologic, histologic, and genetic evidence of disc regeneration in a rat model of degenerative disc disease. The spine journal : official journal of the North American Spine Society 14:1017-1028. doi:

10.1016/j.spinee.2013.11.034

Page $16 / 25$ 
36. Walsh TR, Weinstein JN, Spratt KF, Lehmann TR, Aprill C, Sayre H (1990) Lumbar discography in normal subjects. A controlled, prospective study. The Journal of bone and joint surgery American volume 72:1081-1088

37. Zhang H, Lin CY (2008) Simvastatin stimulates chondrogenic phenotype of intervertebral disc cells partially through BMP-2 pathway. Spine 33:E525-531. doi: 10.1097/BRS.0b013e31817c561b

38. Zhang H, Wang L, Park J, Park P, Yang V, Hollister S, La Marca F, Lin C (2009) Intradiscal injection of simvastatin retards progression of intervertebral disc degeneration induced by stab injury. Arthritis research \& therapy 11:R172. doi: 10.1186/ar2861

39. Zhang H, Wang L, Park JB, Park P, Yang VC, Hollister SJ, La Marca F, Lin CY (2009) Intradiscal injection of simvastatin retards progression of intervertebral disc degeneration induced by stab injury. Arthritis research \& therapy 11:R172. doi: 10.1186/ar2861

40. Zhang Y, Bradley AD, Wang D, Reinhardt RA (2014) Statins, bone metabolism and treatment of bone catabolic diseases. Pharmacological research 88:53-61. doi: 10.1016/j.phrs.2013.12.009

\section{Figures}



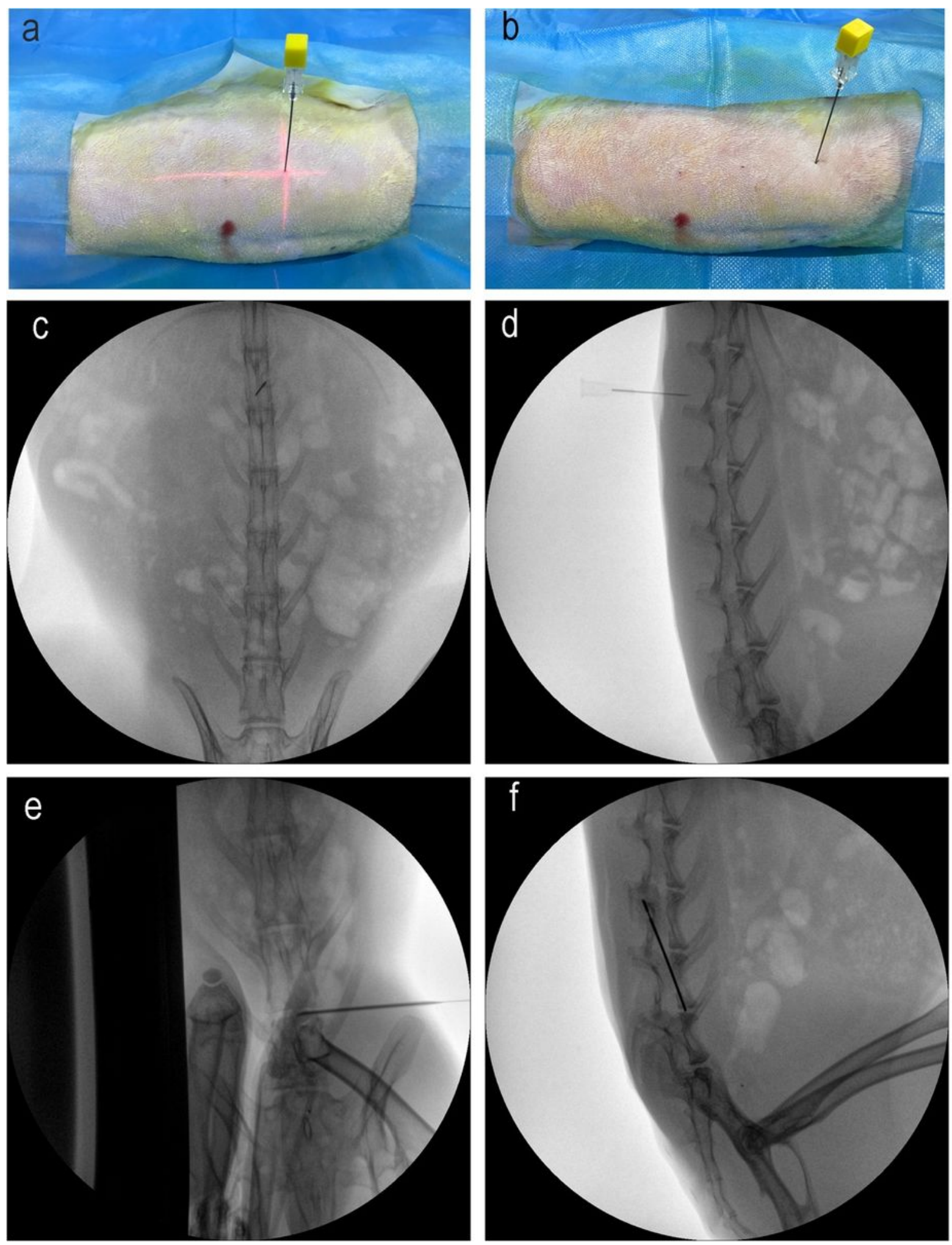

\section{Figure 1}

Intraoperative picture of rabbit DLBP model establishment. $a$. $b$ is the preoperative body surface localization picture; $c, d$ is the preoperative $X$-ray localization picture; $e, f$ is the $X$-ray picture of puncture needle entering the intervertebral disc. 

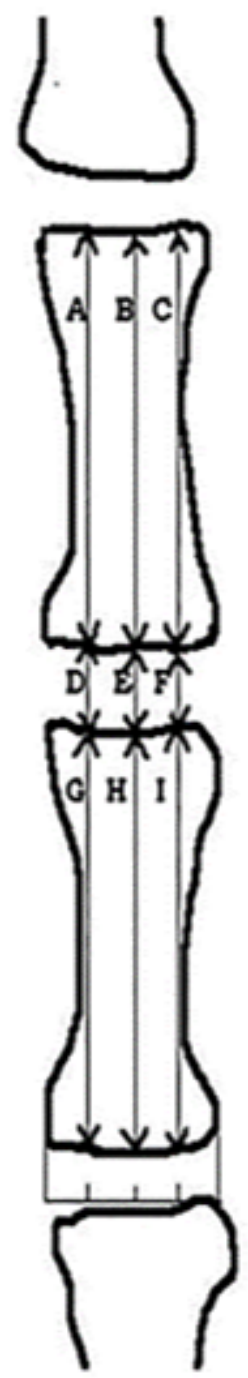

Figure 2

Schematic diagram for calculating the measured value of $\mathrm{DHI}$. 

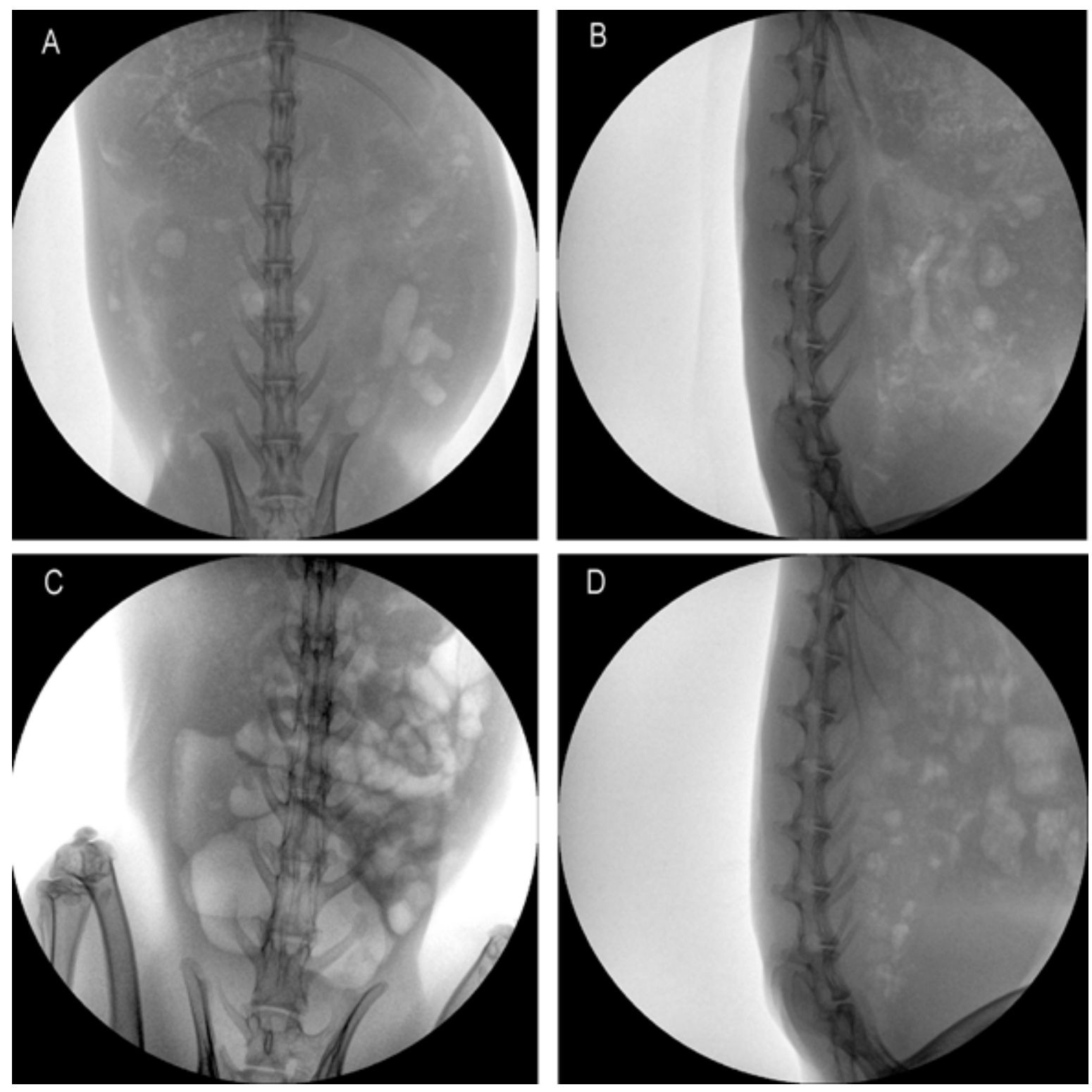

Figure 3

Anteroposterior and lateral films of rabbit lumbar vertebrae taken by $\mathrm{C}$-arm machine for calculating disc height index. A. B is standard anteroposterior and lateral radiographs; $C$ and $D$ are non-standard anteroposterior and lateral radiographs. 

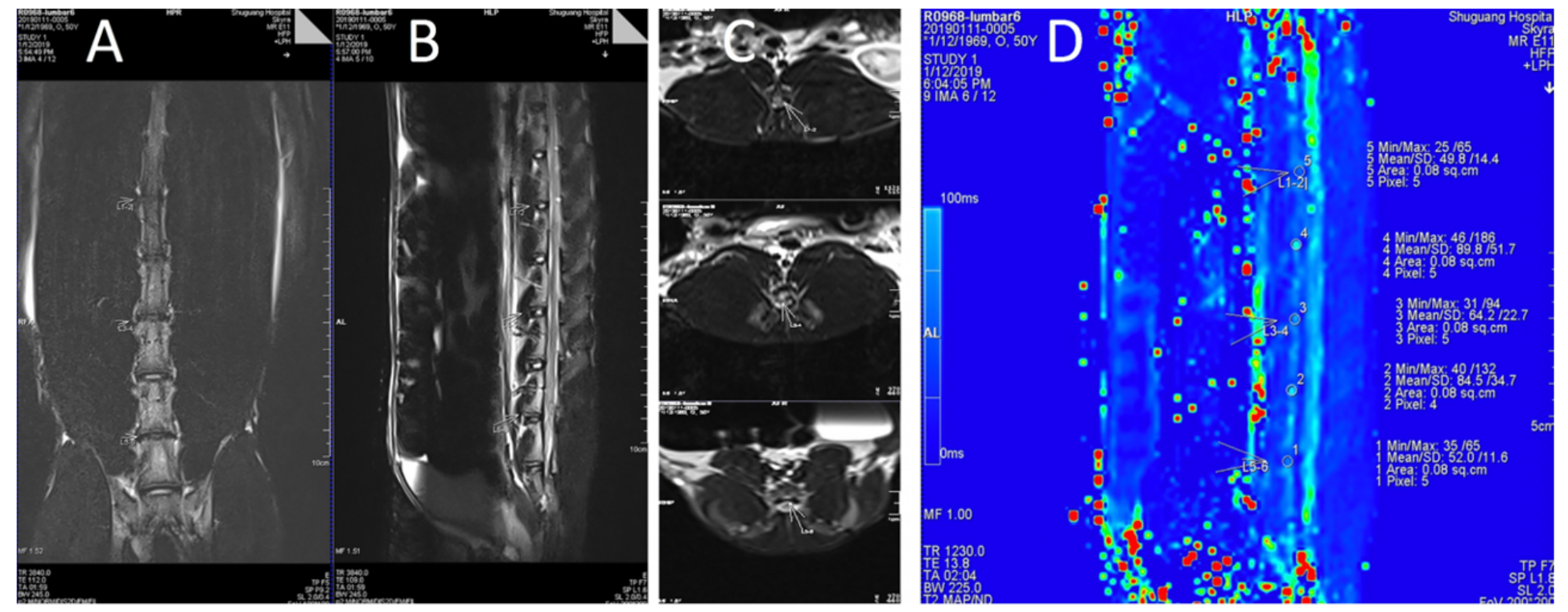

Figure 4

MRI images used to evaluate the rabbit intervertebral disc. $A$ is the coronal image of MRI; $B$ is the sagittal image of MRI; $C$ is the cross-sectional image of MRI; $D$ is the signal intensity of MRI T2 weighted image.

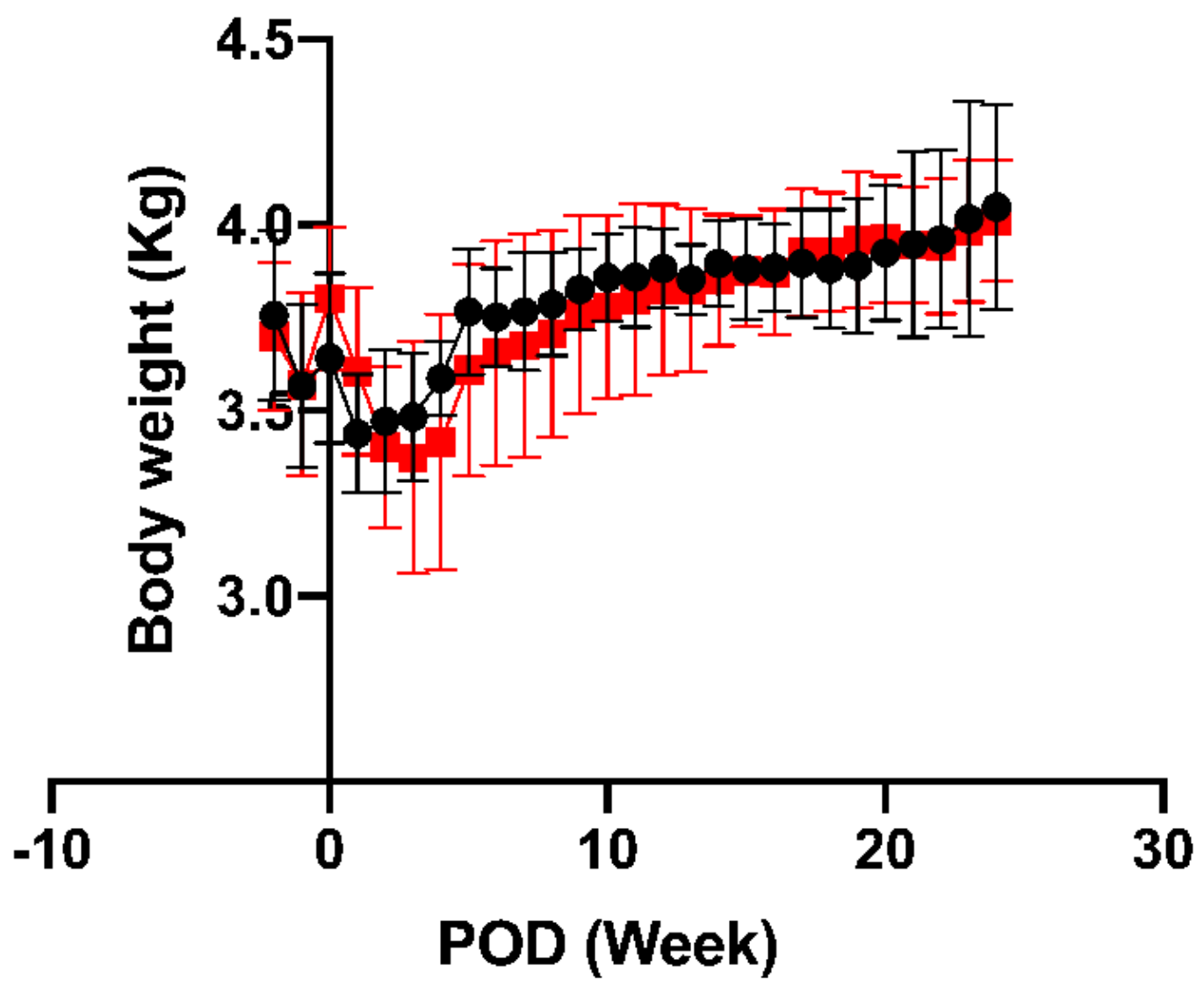

Figure 5 
Effect of intradiscal injection of drugs on animal weight. This graph shows the change of rabbit weight over time. All data were expressed as mean $\pm S D(n=6)$.

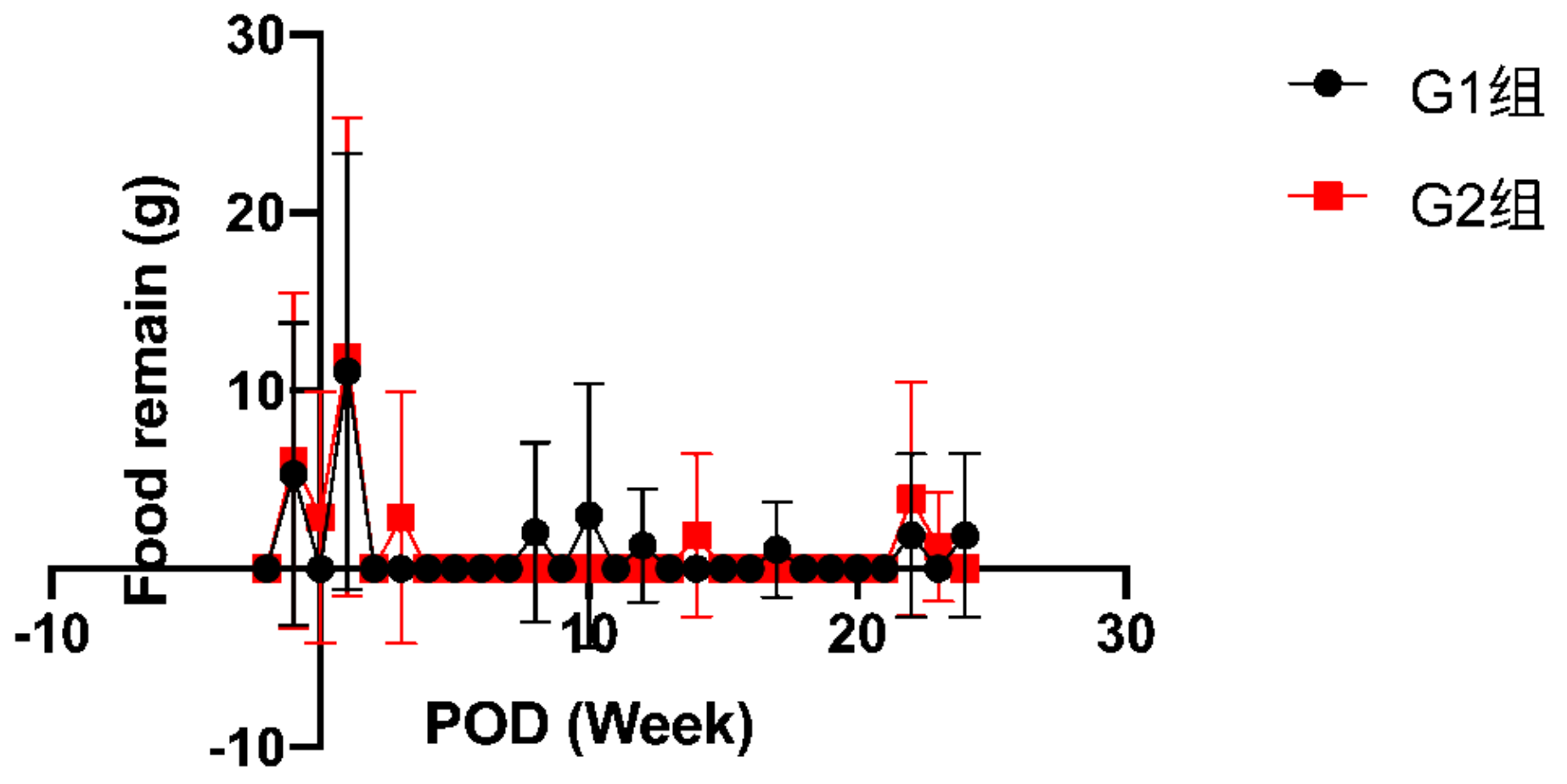

Figure 6

Effect of intradiscal injection of drugs on food residue in animals. The graph shows the change of food residues in rabbits over time. All data were expressed as mean $\pm S D(n=6)$.

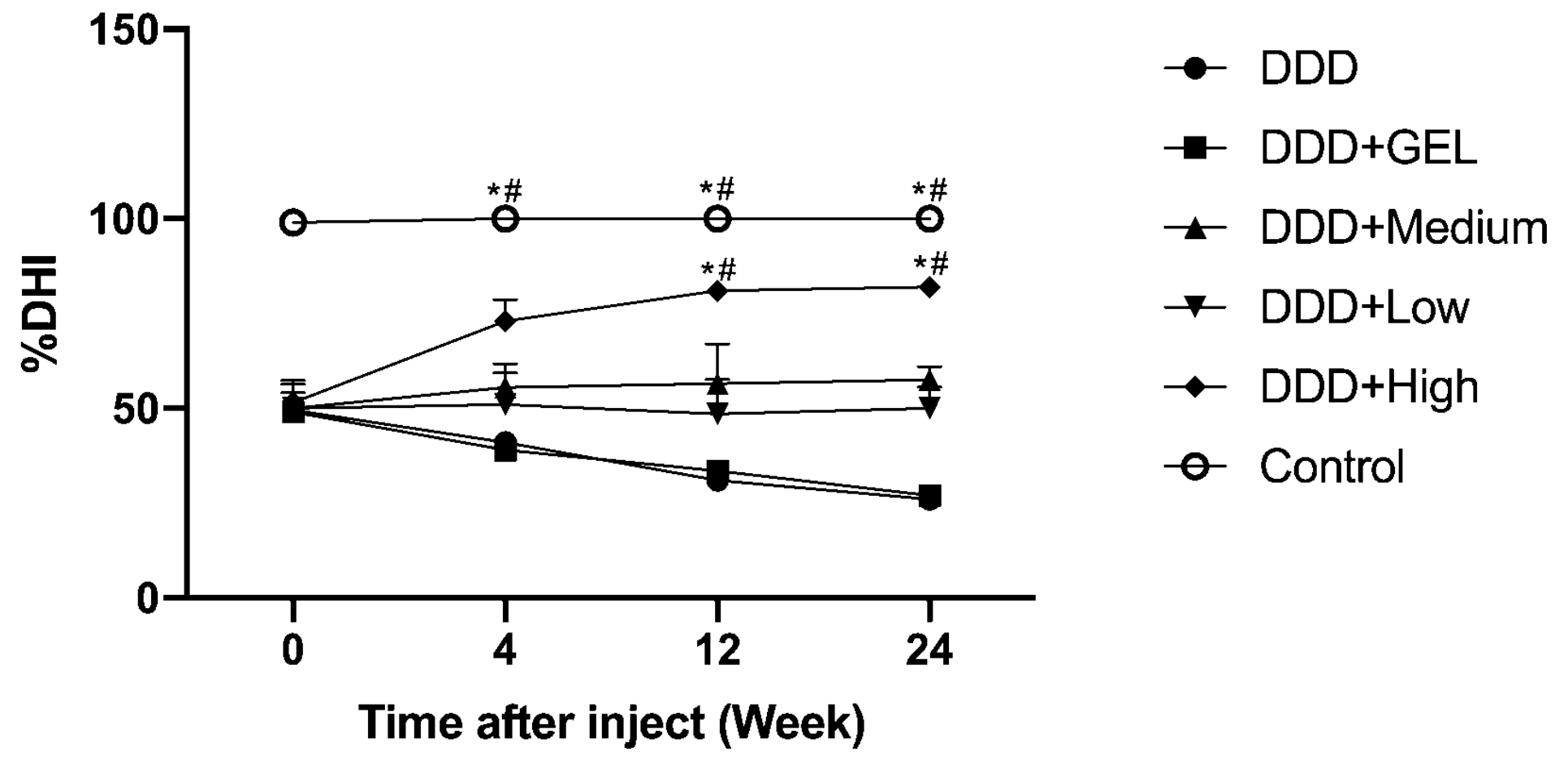

Figure 7 
Effect of intradiscal injection of drugs on intervertebral disc height. This graph shows the change of rabbit disc height index with time. All data were expressed as mean $\pm S D, * P<0.05$ vs. DDD group, $\otimes P<$ 0.05 vs. DDD + gel group $(n=6)$.

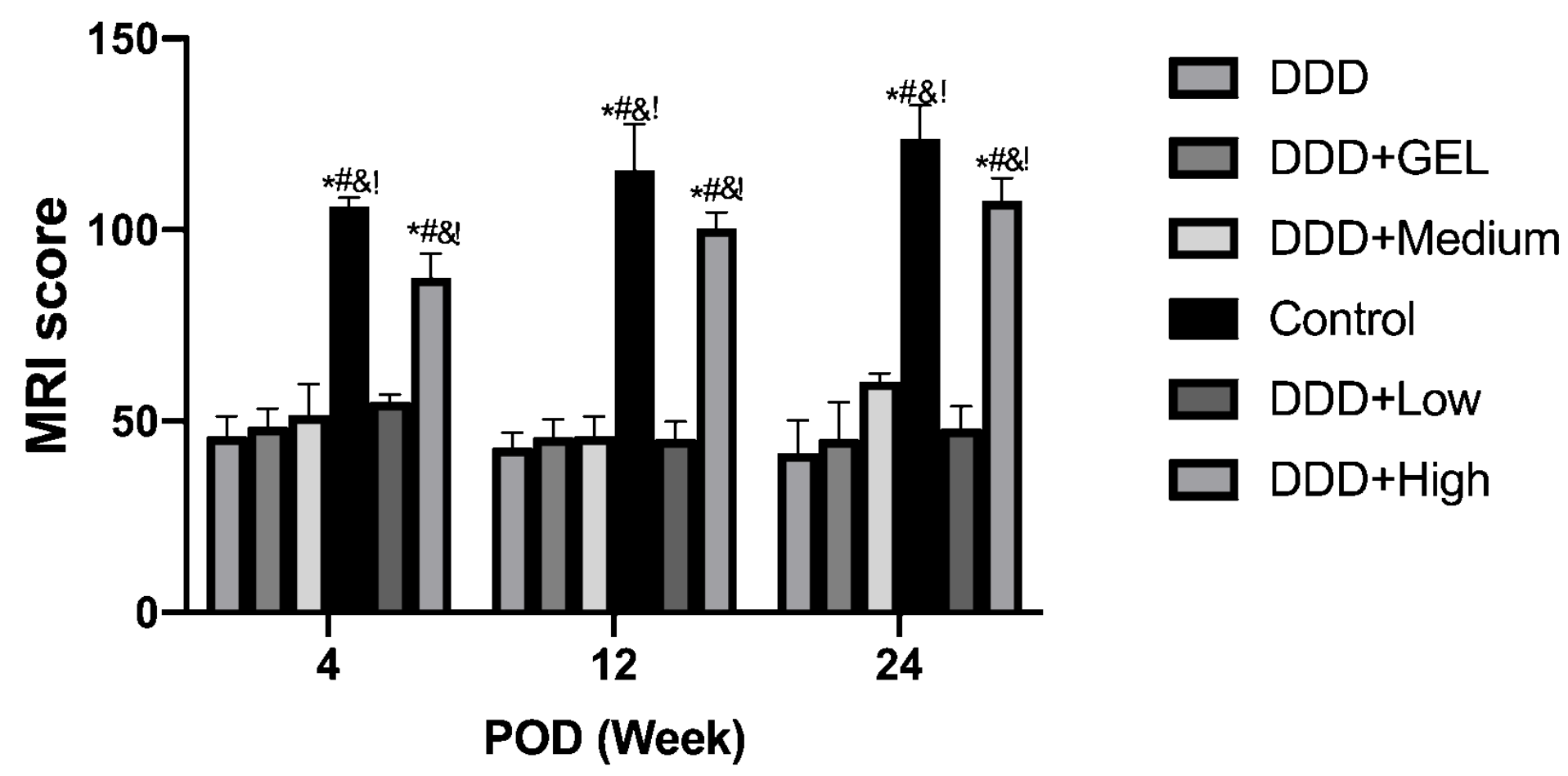

Figure 8

Effect of intradiscal injection of drugs on MRI signal of animal intervertebral disc. This figure shows the change of MRI signal of rabbit intervertebral disc with time. All data were expressed as mean $\pm S D$, * $P<$ 0.05 vs. DDD + gel group, \#P $<0.05$ vs. DDD + gel group, \& $P<0.05$ vs. DDD + low group, $P<0.05$ vs. DDD + medium group $(n=6)$. 


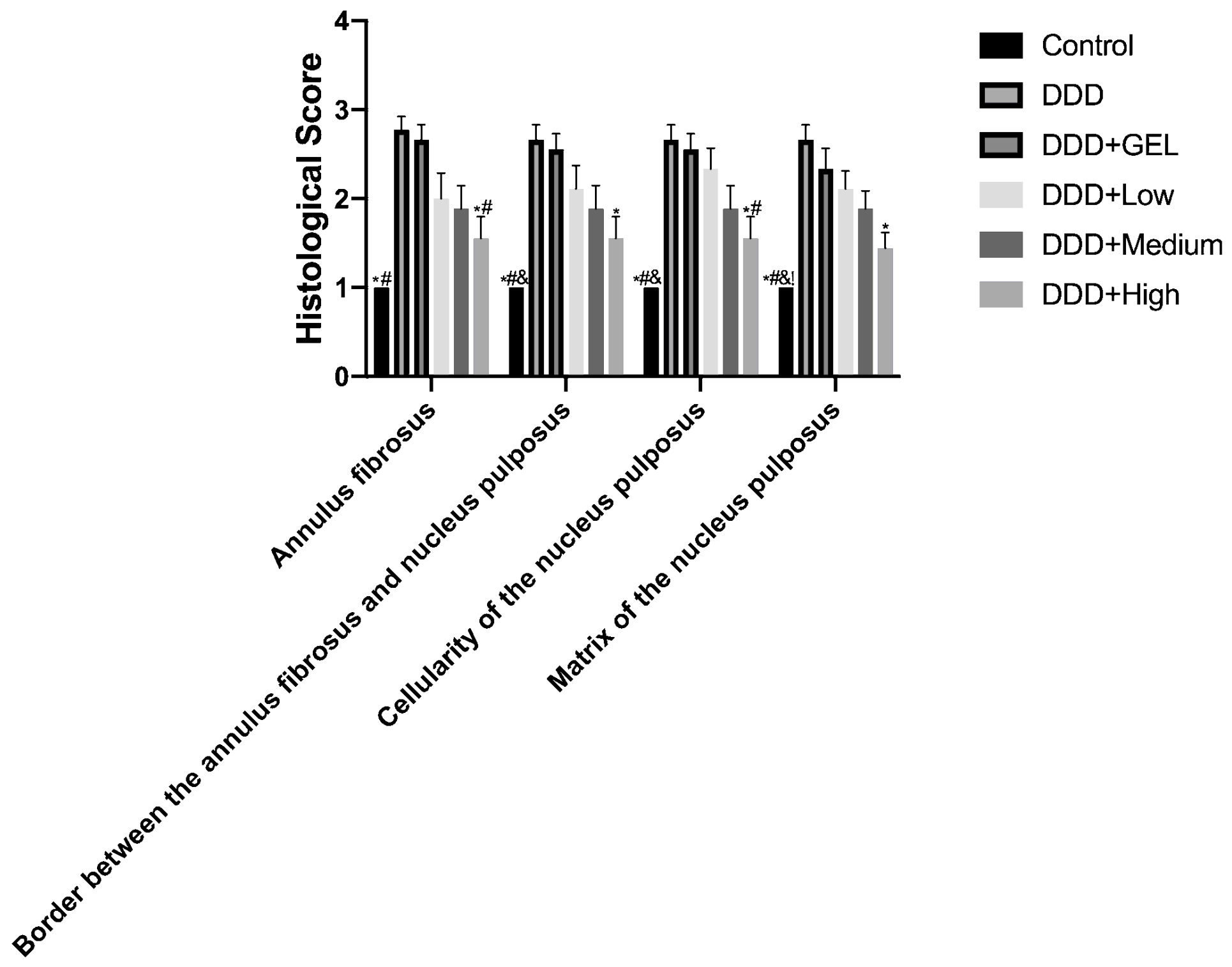

Figure 9

The effect of simvastatin on the histological score of intervertebral disc. All data were expressed as mean $\pm S D, * P<0.05$ vs. DDD + gel group, $\# \mathrm{P}<0.05$ vs. $D D D+$ gel group, $\& \mathrm{P}<0.05$ vs. $D D D+$ low group, $\mathrm{P}<$ 0.05 vs. DDD + medium group $(n=3)$. 


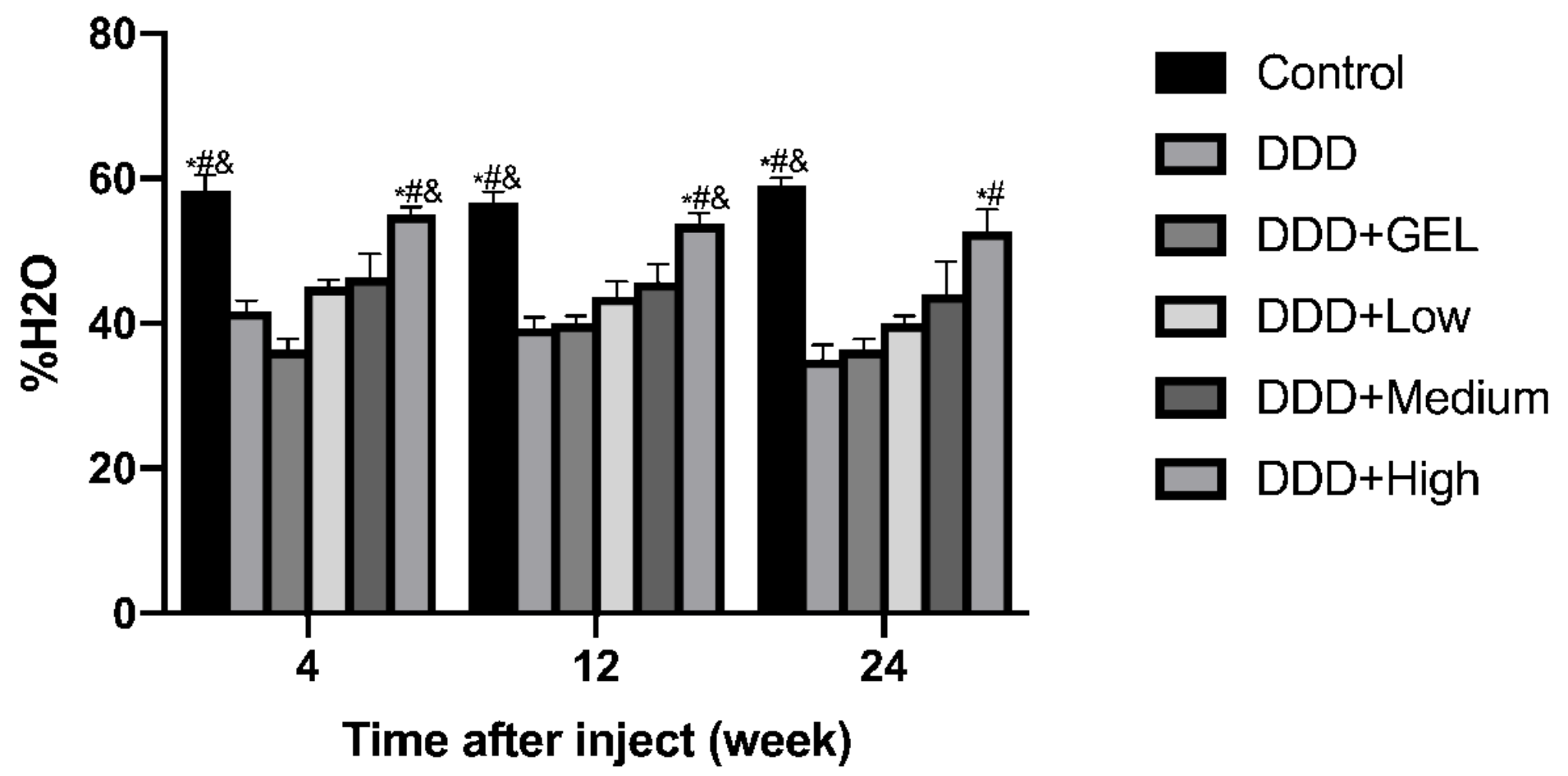

Figure 10

The effect of simvastatin on the water content of intervertebral disc. This graph shows the change of water content of intervertebral disc with time. All data were expressed as mean $\pm S D, * P<0.05$ vs. DDD group, \#P< 0.05 vs. DDD + gel group, \& $P<0.05$ vs. DDD + low group $(n=3)$.

\section{Supplementary Files}

This is a list of supplementary files associated with this preprint. Click to download.

- H2O.pzf 